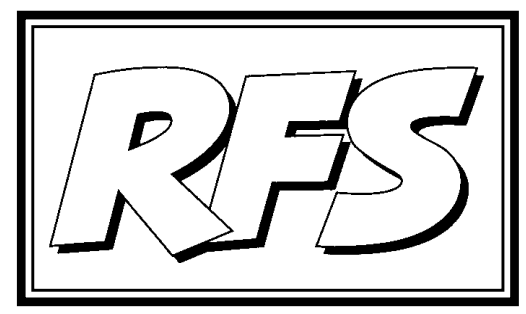

Revista de Fomento Social, 59 (2004), 671-683

\title{
“De la liberación a la resistencia". Un comentario
}

Ildefonso CAMACHO LARAÑA SJ ${ }^{1}$

He leído con interés las páginas de Daniel Izuzquiza. Su lectura me ha resultado fecunda y enriquecedora. Pero me ha suscitado también interrogantes y nuevas reflexiones, que quiero formular en este comentario. La única pretensión de las páginas que siguen es favorecer el diálogo, un diálogo que permita ahondar en los temas que el autor aborda.

\section{Enfoque general del artículo y marco de estas reflexiones}

Como indica su título, lo que Daniel Izuzquiza pretende en este trabajo no es sólo estudiar la teología de la liberación, aunque también se haga un análisis detenido de la misma, sino sobre todo concretar una forma significativa de presencia de la Iglesia en el mundo actual. Y este mundo está considerado desde una doble perspectiva: ante todo, el aspecto que más incidió sobre

1 Profesor de la Facultad de Teología de Granada y de ETEA. 
la teología de la liberación, el social y económico, pero ahora visto desde una óptica nueva, la de la globalización; en segundo lugar, el aspecto de la indiferencia o falta de sensibilidad ante lo religioso, y especialmente ante la dimensión pública de la religión, que hace tan resistente nuestra sociedad a la penetración del mensaje cristiano.

Para afrontar esta cuestión de la presencia de la Iglesia, el autor echa mano de la teología de la liberación, de su ya dilatada historia y de una revisión crítica de la misma hecha desde el contexto norteamericano. Es una perspectiva paradójica en algún sentido, problemática y, en todo caso, original y fecunda: pretende armonizar lo latinoamericano (el "desde donde" se ha elaborado la teología de la liberación) y lo norteamericano (desde donde se la estudia y critica). Y es que la teología de la liberación, que nació bajo el impacto de las grandes injusticias estructurales de nuestro mundo sobre una sociedad con fuerte implantación de lo cristiano, se ha erigido en instancia de crítica y denuncia para esas sociedades más opulentas, donde lo religioso pervive con menos vigor y tiende a ser domesticado por el sistema.

En este tipo de sociedades, entre las que se cuenta la norteamericana, se puede hacer una crítica de la teología de la liberación desde dos enfoques alternativos. El primero tiende a desactivar todo el potencial de denuncia de las estructuras injustas que posee esta corriente teológica: este enfoque está más cerca, lógicamente, del "establishment" y para ella lo religioso es un factor más de estabilidad para todo el sistema. El segundo, en cambio, se abre sin reservas a esa denuncia que viene de las víctimas del sistema, aunque no admita todos sus planteamientos. La diferencia mayor entre estas dos aproximaciones a la teología de la liberación es que, mientras la primera no deja cuestionar la propia realidad desde la que se hace la crítica, la segunda reconoce la responsabilidad de este mundo opulento en la injusticias denunciadas y busca reformular la misión de la Iglesia en estas nuevas coordenadas.

La distinción entre estos dos enfoques críticos, que Daniel Izuzquiza no llega a explicitar, está latente en su estudio y se manifiesta en el temor de que iniciativas surgidas desde el segundo enfoque acaben diluyéndose en el primero. Es un temor en modo alguno infundado, porque es muy grande el peligro de que la religión, y el cristianismo concretamente, sea domesticada por sociedades con mecanismos de poder tan potentes como las nuestras.

Por otra parte, es un hecho que el capitalismo de hoy no es el mismo que el de la época en que la teología de la liberación nació y vivió su primer pe- 
riodo de fuerte expansión. Tras este periodo hemos asistido al fracaso del colectivismo, con consecuencias de un alcance difícil de exagerar. Porque, en primer lugar, el capitalismo ha quedado prácticamente sin alternativas realistas para organizar la economía de las naciones, ya que las contadas experiencias colectivistas que sobreviven ofrecen pocas esperanzas para el futuro. Pero además, en segundo lugar, el capitalismo está adquiriendo dimensiones planetarias: no sólo organiza la economía de todos los países, sino que estructura a la economía mundial como un todo unitario. Ese capitalismo global (que es la base de la globalización) es un dato hoy omnipresente que, si acaso, en la época de mayor florecimiento de la teología de la liberación sólo se intuía.

Con estas observaciones que preceden se comprende mejor el objetivo de Daniel Izuzquiza. Cabría formularlo así: ¿qué puede aportar la teología de la liberación, debidamente corregida y actualizada, para una forma más significativa de presencia de la Iglesia en el mundo actual, y no sólo en los países en desarrollo? A esta cuestión el autor va a responder estructurando todas sus reflexiones en tres momentos: momento descriptivo / momento crítico / momento constructivo. Los comentarios que siguen van a referirse especialmente a éste último, que se pone en relación en el mismo epígrafe con "una eclesiología radical". El autor elabora en esta tercera parte unas propuestas para "traducir" la teología de la liberación, corregida con las observaciones formuladas en el "momento crítico", a la nueva situación del capitalismo globalizado.

\section{La propuesta de comunidades radicales}

En sus propuestas constructivas hay un deseo muy encomiable de implicar a todos los miembros de la Iglesia, sin dejarlo todo en manos de la jerarquía eclesiástica o de ciertas élites eclesiales. Por eso se comienza hablando de las comunidades. Se sugiere, además, que éstas sean "radicales". Se está pidiendo con ello que los cristianos vivan la fe con todas las consecuencias, sin quedarse en medianías, de forma radical. Y este radicalismo, que impregnaría (o debería impregnar) la vida de todos y cada uno de sus miembros, se propone esté inspirado en la teología de la liberación, una vez corregidos los excesos o carencias de ésta.

Esta orientación se ilustra con tres ejemplos tomados de la realidad norteamericana (Catholic Worker Movement, proyecto Ekklesia, Sojourner). En 
la descripción que hace de los mismos se observa una ausencia de compromiso. El mismo autor lo insinúa cuando escribe que en ellos no se ha llegado a "sopesar las implicaciones políticas de esa retirada del espacio público" $[541]^{2}$. Efectivamente, según la descripción que se hace de ellos, estos tres movimientos se han centrado en la vida interna del grupo eclesial (véase la importancia que dan a la liturgia, por ejemplo) y han limitado su proyección social a obras de misericordia. Falta en ellos, en cambio, un verdadero compromiso por la transformación de las estructuras sociales y económicas, incluido el propio sistema económico en su conjunto. Estas ausencias son las que quiere corregir el autor en el apartado siguiente, que lleva por título "Impacto en la transformación social" [541].

No es superfluo detenerse en esos tres movimientos para subrayar lo que aportan, pero también sus carencias. Además de su potencialidad para vitalizar la vida eclesial y la experiencia cristiana de sus miembros, aportan alternativas dentro del sistema: en el seno de un capitalismo que se guía por el lucro y el consumo, los movimientos citados se ocupan de atender a las víctimas y marginados que el mismo sistema genera. Por eso en estos movimientos las obras de misericordia ocupan un lugar importante. Estas obras de misericordia tienen un doble valor: por una parte, afrontan un problema real y le ofrecen soluciones, que tienen como beneficiarios a personas concretas; por otra parte, poseen una dimensión simbólica (son expresión de un modo alternativo de actuar, aunque no llegan a constituir un sistema alternativo). El capitalismo seguirá funcionando como sistema, pero dentro de él surgirán iniciativas para reducir sus efectos negativos, que aspiran a tener un alcance simbólico: no se quedan en lo que se hace, sino que remiten a algo que está más allá de lo que se hace, a un mundo guiado por criterios muy diferentes de lo que es común en nuestras sociedades.

Esta distancia entre la acción concreta de efectos inmediatos y esa otra dimensión que trasciende lo inmediato, es esencial para entender la misión de la Iglesia en lo que tiene de específico, si no queremos reducir ésta a una fuerza social más entre todas aquéllas que se esfuerzan por hacer este mundo más humano. Este remitir a lo que no es inmediato, a otra realidad más honda que sólo se percibe de una forma incoativa e incompleta, pero real, es lo que nos pone en la vía para descubrir lo propio y específico de la Iglesia. La Iglesia se esfuerza por transformar y humanizar este mundo, y lo

2 Estas referencias numéricas entre corchetes remiten a las páginas del artículo de D. Izuzquiza, publicado en este mismo número. 
hace a través de múltiples formas de presencia y compromiso, pero quiere hacer de todo esto un signo de la presencia de Dios mismo y de sus designios sobre el mundo. En esto consiste la actualización que hizo el Concilio Vaticano II de la misión de la Iglesia.

El mismo Daniel Izuzquiza cita un texto esencial de la constitución dogmática sobre la Iglesia, aprobada por el Concilio (Lumen gentium) donde se define la Iglesia desde esta óptica. Y califica dicho texto de "potente definición, aunque todavía general y abstracta" [525]. Dice Lumen gentium: "La Iglesia es en Cristo como un sacramento o como una señal e instrumento". Probablemente considera "general y abstracto" este pasaje porque lo corta aquí injustificadamente, y deja de citar lo que sigue, que es lo que da verdadero contenido a la formulación: “...de la unión íntima con Dios y de la unidad de todo el género humano".

\section{La misión de la Iglesia y el giro eclesiológico del Concilio ${ }^{3}$}

Esta presentación de la Iglesia como sacramento de la unión con Dios y de la unidad del género humano es una de las claves para entender el giro que supuso el Vaticano II en la forma de concebir las relaciones de la Iglesia con la sociedad y la misión de aquélla en el seno de ésta. Para comprender el alcance de este giro tenemos que recordar algunos hitos del desarrollo del Concilio, en el que la Iglesia terminó por ser el eje vertebrador de todos los trabajos.

En efecto, en los últimos días de la primera sesión conciliar (la del otoño de 1962) los padres reunidos llegaron a sentirse perdidos por la cantidad de documentos que le habían sido presentados a estudio y la complejidad de los temas que en ellos se contenían. Fue entonces cuando se elevó la voz de una de las personas más relevantes en el aula, el cardenal Suenens, arzobispo de Malinas Bruselas. Propuso que todos los trabajos del Concilio se estructuraran en torno a la Iglesia, con una doble dimensión: ad intra (su vida interna y su organización) y ad extra (su proyección hacia fuera, sus relaciones con la sociedad). Este planteamiento prosperó. Consecuencia de ello, los dos documentos sobre la Iglesia se convirtieron en las coordenadas de todos los trabajos conciliares: la ya citada constitución Lumen gentium y la constitución

3 Para una explicación de este giro puede verse: I. САмасно, Doctrina Social de la Iglesia. Una aproximación histórica, San Pablo, Madrid, $3^{\text {a }}$ edición, 1998, 285-312, y la bibliografía allí citada. 
pastoral sobre la Iglesia en el mundo de hoy (Gaudium et spes).

Por lo que respecta a Lumen gentium, su elaboración en el concilio no sólo fue larga sino que dio además ocasión para una reflexión en profundidad sobre lo que es la Iglesia en el nuevo contexto: el de la sociedad moderna, secular y pluralista. Asumir las consecuencias de este nuevo contexto va a permitir el giro del Concilio, después de mucho tiempo en que la Iglesia se había aferrado a la sociedad antigua y al lugar que en ella le correspondió durante siglos.

Este giro estaba todavía muy lejos del primer borrador de documento sobre la Iglesia que se presentó a los padres conciliares. Este texto, que había sido redactado por la comisión preparatoria del Concilio desde su marcado talante conservador, encontró tal oposición en el aula que fue rechazado sin paliativos. Las principales críticas que se le hicieron detectaban que sus autores no habían tomado conciencia del cambio que se había ido produciendo en los últimos siglos, ni comprendían cómo la modernidad se había sacudido ya definitivamente la tutela que durante siglos la institución eclesial ejerció sobre ella. Una sociedad secular ya no tiene a lo religioso como elemento estructurante, ni acepta las orientaciones y dictámenes de la jerarquía religiosa como determinantes para el orden social. La forma de estar o el lugar de la Iglesia en la sociedad debe ser concebido de un modo diferente. Hablando en términos teológicos, la misión de la Iglesia debe buscar nuevas formas de expresión y de realización.

Más aún, en los debates conciliares se puso de manifiesto que era el concepto mismo de misión el que había sido olvidado en la época antigua y en el régimen de cristiandad, ahora puesto en crisis. Las "misiones" sólo se entendían para el envío de personas (por lo general, clérigos o religiosos) a territorios donde el cristianismo estaba escasamente implantado o la Iglesia carecía de efectivos humanos suficientes para desarrollar sus actividades. Pero en el mundo occidental la misión, en el sentido estricto de anuncio del Evangelio, había sido sustituida por tareas que podríamos llamar "de mantenimiento", más propias de sociedades que se consideraban cristianizadas en su totalidad.

La modernidad hacía ya muy problemático este supuesto de sociedad cristiana. Reivindicar la posición que la Iglesia ocupaba en este tipo de sociedad, ya en trance de desaparición, era cerrar los ojos a una nueva realidad que se imponía a todas luces. Pero reconocer esta nueva realidad era asumir el reto de reformular la misión de la Iglesia. Esta será la gran tarea 
del Concilio. ¿Cómo lo hará? Para empezar, con una autocomprensión de la Iglesia basada en categorías nuevas: no exactamente de nuevo cuño, sino más bien recuperadas de la tradición cristiana de los primeros siglos. Estas categorías tendrán en su núcleo mismo la idea de misión: la Iglesia se define desde el estar en misión, es decir, como enviada al mundo con un mensaje que transmitirle. Se comprende que esto sintoniza mejor con los primeros tiempos cristianos y el ambiente en que la Iglesia se desenvolvió entonces.

Frente a los conceptos más tradicionales, elaborados en la etapa de una fuerte conflictividad entre la Iglesia y la sociedad moderna, muy presentes en el primer borrador ya citado, el Concilio va a echar mano de la categoría de misterio y sacramento de salvación para definir a la Iglesia ${ }^{4}$.

Esta larga digresión permite comprender mejor aquella definición de la Iglesia en Lumen gentium que recogía Daniel Izuzquiza, así como la importancia de considerar la fórmula completa y sin recortes. Recordémosla: $L a$ Iglesia es en Cristo como un sacramento o como una señal e instrumento de la unión íntima con Dios y de la unidad de todo el género humano. ¿Cuál es el significado concreto de sus términos? "Sacramento" significa ser a la vez "señal e instrumento". Es decir, se "anuncia" algo (señal) y al mismo tiempo "se hace realidad de alguna manera" (instrumento). Y eso que se anuncia y se hace realidad son dos cosas complementarias: que el ser humano está abierto a la trascendencia y está llamado a vivir en fraternidad.

La misión de la Iglesia consiste en anunciar y hacer realidad esta doble dimensión de la existencia humana, precisamente cuando todo lo que nos rodea en nuestro mundo parece inducir a pensar lo contrario: la trascendencia parece un discurso vano e inútil, mientras que hacer de este mundo una fraternidad se antoja hoy una utopía tan ingenua como ilusoria.

Dos aspectos deben ser destacados en esta comprensión de la Iglesia como sacramento: su distancia respecto a las concepciones tradicionales antes aludidas y su virtualidad para responder mejor a las condiciones de la sociedad moderna.

Ante todo, la Iglesia asume que no dirige a la sociedad desde una autoridad reconocida por todos, ni siquiera aspira ya a ello -aunque lo hiciera durante siglos en el régimen antiguo de cristiandad-, porque la modernidad ya no lo admite desde su propio paradigma.

4 Dichos conceptos, que servían de coordenadas en el primer borrador, eran: la Iglesia como "Cuerpo de Cristo" y la Iglesia como "sociedad perfecta, desigual y jerárquicamente constituida". 
Ahora bien, eso no significa que la Iglesia tenga que recluirse en el ámbito de la privacidad, como muchas veces se pretende: sigue teniendo una vocación de presencia pública, que se realiza individual e institucionalmente (los creyentes en su vida de cada día, la comunidad eclesial en su visibilidad institucional).

Esta presencia se expresa ahora en forma sacramental, que se adapta mejor a las condiciones de la modernidad: no es imposición coactiva desde una autoridad por todos reconocida, sino propuesta hecha desde la coherencia de vida (testimonio y compromiso) y desde la palabra que la acompaña siempre que el mensaje implícito en la vida exija ser explicitado y explicado.

Esto significa que ha cambiado el sujeto que actúa y obliga a modificar el mismo contenido que se da a la palabra "Iglesia": la Iglesia en misión no son ya los que tienen una responsabilidad ministerial o pastoral (como se tendía a entender hasta entonces), sino todos los creyentes. Aquí es donde adquiere todo su sentido la otra categoría clave de Lumen gentium, la de pueblo de Dios $^{5}$.

Pueblo de Dios es la comunidad de los llamados para la misión de hacer presente el Evangelio en el mundo: esa llamada, y no otra cosa, es la esencia del ser cristiano. La idea de la Iglesia anterior al Vaticano II había subrayado la diversidad de miembros en la Iglesia: jerarquía, laicos, religiosos. Lumen gentium comienza afirmando la igualdad: todos llamados para hacer de la vida envío y misión. Que esa misión se realice después de manera diferente, según tareas y funciones, no cuestiona esta igualdad previa, pero esencial.

En resumen: una Iglesia que se entiende desde la misión y una misión que es consustancial a la condición de cristiano.

Hasta aquí la eclesiología del Vaticano II no ha hecho sino confirmar la pertinencia de la orientación fundamental del artículo de Daniel Izuzquiza que venimos comentando. Pero es ahora donde comienzo a ver algunos puntos que merecen ulterior precisión. Precisamente cuando abordamos algunas consecuencias de esa interpretación de la misión en términos de sacramento.

5 Daniel Izuzquiza afirma que la categoría central de la Lumen gentium es la de "pueblo de Dios" [526 y 545]. Esta afirmación requiere ser matizada: "misterio" es el concepto clave, al que "pueblo de Dios" sirve como complemento. Eso es lo que se deduce de la lectura de Lumen gentium analizando los capítulos 1 y 2 y la relación entre ellos. "Pueblo de Dios" es importante para subrayar la igualdad esencial de todos los bautizados, como algo previo a las distintas funciones que se atribuyen luego a unos y otros. Volveremos sobre este punto. 
Porque es aquí donde es indispensable distinguir nítidamente entre la Iglesia, la sociedad y el Reino de Dios, una distinción que merece una atención especial para evitar ambigüedades del pasado y posibles ambigüedades del futuro. Es desde aquí desde donde quiero ofrecer algunas sugerencias en diálogo con el trabajo de Daniel Izuzquiza.

\section{La misión y sus coordenadas: Iglesia, sociedad, reino de Dios}

En efecto, en el antiguo régimen de cristiandad Iglesia y sociedad se identificaban, eran coextensivas: mientras no se demostrara lo contrario, el ciudadano era cristiano; no ser cristiano era posible, pero resultaba atípico en una sociedad que se estructuraba sobre el patrón de la Iglesia y recibía de ésta legitimidad y consistencia. En la sociedad moderna, esto ya no es pensable: la Iglesia vive en la sociedad, es un colectivo que forma parte de ella. Y probablemente nunca volverá a identificarse con ella. Más aún, la Iglesia nunca puede ser propuesta como un modelo concreto a imitar, puntualmente y en todos sus extremos, por la sociedad, ni tampoco tiene por qué organizarse en todo según los moldes de la sociedad moderna. Es preciso mantener que son dos realidades esencialmente diferentes.

Más aún, desde una visión cristiana, ambas, Iglesia y sociedad, tienen como referente el reino de Dios. La Iglesia lo anuncia y lo hace realidad de forma germinal o incoativa: sacramentalmente. La sociedad está llamada a convertirse en el reino de Dios, y ése es el horizonte final de la historia, cuando la historia llegue a su consumación. Pero en el transcurso de la historia, siempre se mantendrá la distancia entre sociedad y reino de Dios, mientras que la Iglesia se esforzará por subrayar esta relación anunciándola con su vida y con el compromiso de sus miembros: el horizonte del reino servirá siempre de norte para este compromiso, como un empeño por ir transformando la sociedad de acuerdo con los criterios del Evangelio. Y lo hará con la conciencia de esa tensión nunca resuelta entre lo que se anuncia y lo que existe, entre la realidad imperfecta de hoy y la realidad en plenitud del reino de Dios.

Las ambigüedades a que nos referíamos más arriba derivan de no mantener siempre nítida la distinción entre Iglesia, sociedad y reino de Dios. 


\section{Algunas ambigüedades a evitar}

El "momento constructivo" del artículo que comentamos se divide en dos apartados: "Comunidades radicales" e "Impacto en la transformación social". A partir de esta situación cabe hacer algunas consideraciones.

Esas comunidades radicales o comunidades que viven la fe con radicalidad son de gran importancia para la misión de la Iglesia, pero con una condición: que no se las proponga a la sociedad como modelos de aplicación inmediata, a los que ésta tendría que amoldarse. Se trata, en el fondo, sólo de mantener la diferencia ya explicada entre Iglesia y sociedad.

¿Qué aporta, entonces, la Iglesia a la sociedad? A clarificarlo ayuda el apartado dedicado al "Impacto en la transformación social". Creo que en las propuestas constructivas del artículo pueden distinguirse tres tipos de aportaciones de la Iglesia a la sociedad:

$1^{\mathrm{a}}$ Propuestas concretas y fragmentarias de carácter técnico, para mejorar aspectos particulares de la vida social. En ellas se incluirían las que se refieren a mejoras del Estado de bienestar [542, 544]. Sin embargo, este tipo de propuestas no parecen satisfacer plenamente al autor, aunque no las excluya: quizás le parecen excesivamente técnicas y susceptibles de reducir la visibilidad del mensaje. En mi opinión eso no debería servir para minusvalorar su importancia, ya que se sitúan en el mismo nivel de otras propuestas venidas desde perspectivas religiosas y/o ideológicas diversas: y en ese nivel, el diálogo de los cristianos con personas de otras tendencias es más directo y concreto, más creíble para los otros interlocutores.

$2^{\mathrm{a}}$ Propuestas que tienen un carácter más testimonial o profético, más estrictamente sacramental en el sentido explicado. Como en el caso anterior, también son concretas y responden a problemas bien delimitados. Por ejemplo, crear una comunidad real de nacionales e inmigrantes con o sin papeles [544]. Sin duda estas propuestas tienen también un gran valor, pero normalmente no son universalizables: en este sentido no son alternativas reales: no cabría pensar que el problema de la inmigración clandestina se resolvería con sólo generalizar ese tipo de comunidades. Ahora bien, no por eso carecen de valor: porque ayudan a tomar conciencia de ciertos problemas y a sensibilizar ante actitudes y valores alternativos. El peligro estriba sólo en presentarlas como alternativas reales. 
$3^{\text {a }}$ Propuestas que tienen carácter global. Ahí se insertaría la propuesta de un socialismo alternativo, sin propiedad privada ni ejércitos [543]. Propuestas de este tipo son las más problemáticas y discutibles. En primer lugar, porque tendrían que implicar a toda la Iglesia si quieren tener alguna operatividad. Ahora bien, ¿puede vincularse a la Iglesia con un sistema de organización global de la sociedad? Pero son problemáticas, además, por la misma vulnerabilidad de la propuesta: ¿qué valor tiene a la vista de las realizaciones históricas que se han hecho en su nombre? ¿pueden atribuirse los fracasos del socialismo real sólo a la maldad de los seres humanos, concretamente de los gobernantes, como se afirma muchas veces? ¿y no resulta demasiado ingenua una propuesta que no desciende a las formas concretas de aplicación (qué socialismo...)? Pero la dificultad principal es, de nuevo, la ambigüedad: ahora, el peligro de confundir la sociedad terrena y el reino de Dios. ¿Habría que decir, en último término, que el reino de Dios será socialista y no capitalista? Todo esto no significa que tengamos que resignarnos con el capitalismo y renunciar a plantear siquiera la posibilidad de una alternativa global al mismo: pero habría que hacerlo desde una conexión más estrecha y directa con la realidad y con una consideración más rigurosa de ésta.

\section{Algunas formulaciones que resultan menos aceptables}

Quizás el peligro potencial de caer en ambigüedades, a que nos hemos referido varias veces, se hace realidad en las dos páginas conclusivas. Esta conclusión, que se titula "El Cuerpo de Cristo como eclesiología radical" [545-547], aporta algunas claves que abonan esas reservas manifestadas en el apartado anterior sobre las "propuestas constructivas" (reservas que estarían menos justificadas si no fueran seguidas de esta conclusión).

Lo que se plantea ahora es buscar una alternativa global real al capitalismo. La cuestión es muy digna de ser planteada. Pero uno duda de que la respuesta tenga que ser "finalmente teológica", o de que haya que buscar "un marco teológico en el que encarnar nuestras propuestas", o que el camino sea el de una eclesiología radical [545].

Este marco teológico se propone que sea el concepto de Cuerpo de Cristo, que se considera más adecuado que el concepto escogido por el Vaticano II, el de pueblo de Dios [545]. Es paradójico que ahora se proponga hacer justo 
lo contrario de lo que hizo el Concilio cuando relegó a segundo término el concepto de Cuerpo de Cristo y lo sustituyó por el de pueblo de Dios. De todos modos, las razones que tuvo el Concilio para esta giro tienen poco que ver con las que se invocan aquí para esta vuelta atrás.

¿Por qué se decidió el Concilio a este cambio? Porque Cuerpo de Cristo resultaba incompleto: explicaba muy bien la estructura interna de la Iglesia, pero olvidaba su proyección exterior y la misión, tan necesaria en la nueva situación de la modernidad y tan nuclear en la eclesiología de los orígenes cristianos.

¿Por qué propone ahora Daniel Izuzquiza abandonarlo? Porque ha dejado de ser un sujeto colectivo "lo suficientemente fuerte como para revertir la historia" [545]. Pero nunca se fijó el Concilio en este aspecto para optar por la categoría de pueblo de Dios. Es más, esta forma de entenderlo contradice de lleno el contenido que le dio el Vaticano II inspirándose en la tradición más antigua de la Iglesia, muy vinculada además con el Antiguo Testamento. Tal como lo entiende Daniel Izuzquiza, es un concepto sociológico (que contrapone pueblo a élites), distinto del concepto teológico usado por el Concilio, que pretende incluir a todos (jerarquía, laicos, religiosos) y subraya la igualdad esencial de todos.

Pero más problemático resulta presentar al Cuerpo de Cristo como alternativa al modelo global capitalista. Me parece que es forzar el concepto teológico de Cuerpo de Cristo pretender que en él se "nos habla clara y directamente sobre la tortura, la violencia doméstica a las mujeres, los corredores de la muerte, los abusos sexuales a menores, el aborto, la anorexia, la bulimia, los embarazos adolescentes, la violación" [545-546]. Si se quiere utilizar como simple metáfora, vale. Pero ¿hasta el extremo de afirmar, por ejemplo, de los sindicatos que en ellos "todos los hombres son hermanos"? [546].

Más sorprendente aún es la afirmación de que "el Cuerpo de Cristo edifica la Iglesia como una alternativa real y visible al sistema dominante" [546]. Aquí es donde me parece ver confirmado mi temor de que ciertas expresiones, en sí sólo ambiguas, desemboquen en confusiones inaceptables que terminan identificando a la Iglesia con la sociedad y con el reino de Dios. Y no deja de extrañar también que el tema del reino de Dios, en cambio, no merezca un tratamiento expreso en el artículo, siendo como es un referente esencial para la misión y para la misma concepción de la Iglesia.

La última cita de dos pensadores anarquistas (jprecisamente anarquistas!) 
confirma esta confusión invocando la autoridad de San Agustín, pero interpretándolo desde la óptica de corrientes posteriores a él, que utilizaron sus ideas sobre las dos ciudades para legitimar el sistema de cristiandad (nos referimos al llamado "agustinismo político").

\section{Conclusión}

Las reflexiones que preceden pueden parecer producto de disquisiciones teológicas alejadas de la realidad. Pero las relaciones de la Iglesia con la sociedad moderna obliga a muchos matices para no caer en nostalgias del pasado (no ausentes de ciertas reivindicaciones que no dejan de oírse) ni contentarse con fórmulas ambiguas, susceptibles de derivar en utopías estériles o en formas solapadas de recuperar el poder perdido. Esta búsqueda de equilibrio no es sólo una cuestión teórica, sino un problema eminentemente práctico: lo que muchas veces no encontramos en la Iglesia son personas $\mathrm{y} / \mathrm{o}$ instituciones que ofrezcan respuestas satisfactorias, en todo coherentes con el impulso misionero de la Iglesia y las reglas del juego vigentes en una sociedad secular y pluralista. ¿No se confirma aquí aquello de que la mejor práctica es una buena teoría? Ojalá estas páginas hayan ayudado, desde el diálogo con el trabajo de Daniel Izuzquiza, a buscar caminos para la presencia de la Iglesia en nuestra sociedad. 